\title{
Multiprofissionalidade e interprofissionalidade em uma residência hospitalar: o olhar de residentes e preceptores
}

Thaise Anataly Maria de Araújo(a)

Ana Claudia Cavalcanti Peixoto de Vasconcelos ${ }^{(b)}$ Talitha Rodrigues Ribeiro Fernandes Pessoa ${ }^{(\mathrm{c})}$

Franklin Delano Soares Forte ${ }^{(\mathrm{d})}$

Araújo TAM, Vasconcelos ACCP, Pessoa TRRF, Forte FDS. Multiprofessionality and interprofessionality in a hospital residence: preceptors and residents' view. Interface (Botucatu). 2017; 21(62):601-13.

We sought to understand the perception of residents and preceptors regarding multiprofessionality and interprofessionality of a Multiprofessional Integrated Residence in Hospital Health. A qualitative approach study was carried out, involving focus groups as the data production strategy, using Bardin's content analysis. Concepts of multiprofessionality and interprofessionality are still weak. However, tools have been listed that can assist in this realization to foster the collaborative work. There is confusion and duality in the recognition of the role of residents in practice scenarios. The preceptor is an important actor in Multiprofessional Residences in Health. Despite the perceived progress, the feasibility of interprofessionality is still a challenge to the health sector. In this context, continous educational processes based on interprofessional education, are strategic tools.

Keywords: Team work. Preceptorship. Interprofessional education.

Interprofessional collaboration.

Multiprofessional residence in healthcare.
Buscou-se compreender a percepção de residentes e preceptores sobre a multiprofissionalidade e a interprofissionalidade de uma Residência Integrada Multiprofissional em Saúde Hospitalar. Foi realizado um estudo com abordagem qualitativa, envolvendo o grupo focal como estratégia de produção de dados, apreciados por meio da análise de conteúdo de Bardin. Na prática, os conceitos sobre multiprofissionalidade e interprofissionalidade ainda são fragilizados. Contudo, foram elencadas ferramentas que podem auxiliar nessa efetivação, inclusive, com vistas ao fomento do trabalho colaborativo. Há confusão e dualidade quanto ao (re)conhecimento do papel dos residentes nos cenários de prática. O preceptor consiste em um importante ator nas Residências Multiprofissionais em Saúde. Apesar dos avanços percebidos, a viabilização da interprofissionalidade ainda se configura como um desafio do setor saúde. Nesse contexto, os processos formativos contínuos, com base na educação interprofissional, constituem ferramentas estratégicas.

Palavras-chave: Trabalho em equipe. Preceptoria. Educação interprofissional. Colaboração interprofissional. Residência multiprofessional em saúde. (a,b) Departamento de
Nutrição, Centro de
Ciências da Saúde,
Universidade Federal
da Paraíba. Cidade
Universitária, s/n,
campus I, $2^{\circ}$ andar do
Centro de Ciências da
Saúde, Castelo Branco
I. João Pessoa, PB,
Brasil. 58059-900.
thaisearaujo_nutri@
yahoo.com.br;
anacpeixoto@
uol.com.br
(c,d) Departamento de
Clínica e Odontologia
Social, Centro de
Ciências da Saúde,
Universidade Federal
da Paraíba, campus
universitário I. João
Pessoa, PB, Brasil.
talitha.ribeiro@
yahoo.com.br;
franklinufpb@
gmail.com 


\section{Introdução}

A reordenação da formação, tanto na graduação como na pós-graduação, tem mobilizado reflexões sobre a necessidade do trabalho em equipe, de práticas colaborativas e da educação interprofissional $(E I P)^{1,2}$. É neste contexto que se insere o desenvolvimento das Residências Multiprofissionais em Saúde (RMS), consideradas alternativas importantes no cenário da formação e para o Sistema Único de Saúde (SUS).

As RMS são pautadas em arcabouço teórico e pedagógico que corroboram os princípios e as diretrizes do SUS, associando o aprendizado à prática, de maneira a problematizar o modelo técnico-assistencial. Desta forma, vislumbra-se o ensino-serviço com enfoque na humanização da atenção e ampliação da compreensão da integralidade, ao passo que o processo de trabalho pode ser (re)construído no cotidiano do serviço ${ }^{3}$.

Entretanto, a literatura aponta imprecisões quanto às definições de alguns termos ${ }^{4}$. Segundo Alvarenga et al. ${ }^{5}$, a fragmentação do cuidado é comum na multiprofissionalidade, a qual seria a justaposição de disciplinas distintas, em que os saberes especializados balizarão a atuação de cada profissional. Já a interprofissionalidade vincula-se: à noção do trabalho em equipe de saúde, marcado pela reflexão sobre os papéis profissionais, a resolução de problemas e a negociação nos processos decisórios, a partir da construção de conhecimentos, de forma dialógica e com respeito às singularidades e diferenças dos diversos núcleos de saberes e práticas profissionais ${ }^{6}$.

Extrapolar o trabalho em equipe multiprofissional, para uma perspectiva de interprofissionalidade, reduz custos e melhora a produção do cuidado aos usuários ${ }^{7-13}$, especialmente em se tratando de situações de elevada complexidade, como são os casos das residências multiprofissionais hospitalares ${ }^{14}$.

A Organização Mundial da Saúde (OMS)7 propôs a definição para a EIP: "É quando estudantes ou profissionais de dois ou mais cursos, ou núcleos profissionais, aprendem sobre os outros, com os outros e entre si". Na conjuntura das RMS, a EIP constitui uma estratégia que oportuniza o desenvolvimento do trabalho coletivo efetivo, com o intento de otimizar a qualidade da atenção à saúde $e^{7,8,15}$.

Assim, fortalecer a EIP favorece a implementação da prática colaborativa em saúde, uma vez que esta pressupõe a incorporação da experiência de profissionais de diversos núcleos do saber, estimulando a comunicação entre eles e a tomada de decisão, com vistas a consolidar a integralidade do cuidado ${ }^{10,11}$. Destaca-se, ainda, a importância do envolvimento de diferentes atores no processo, para além dos profissionais da área, o que amplia o escopo de atuação destes e as conquistas dos objetivos de saúde ${ }^{10}$.

A OMS ${ }^{10}$ ainda aponta que as equipes de saúde de diferentes núcleos profissionais, que trabalham na perspectiva interprofissional, qualificam os serviços de saúde ofertados aos usuários, ao passo que há compreensão das habilidades dos membros que as compõem, assim como compartilhamento e gerenciamento dos casos. Deste modo, é possível considerar as seguintes potencialidades dessa forma de atuação: a) otimização das práticas e produtividade no ambiente de trabalho; b) melhoria dos resultados obtidos, mediante recuperação e segurança dos pacientes; c) ampliação da confiança dos trabalhadores da saúde; d) melhoria do acesso à assistência de saúde.

A Residência Multiprofissional e a em Área Profissional da Saúde foram propostas em $2005^{16} \mathrm{e}$ devem ser desenvolvidas conforme as necessidades e realidades locais e regionais ${ }^{17}$.

Nesse escopo, configura-se o cenário desta pesquisa: a Residência Integrada Multiprofissional em Saúde Hospitalar (RIMUSH), vinculada a um centro de uma instituição de Ensino Superior do Nordeste do Brasil, dentro de um hospital universitário (HU).

Nesse cenário de aprendizagem, o residente desenvolve suas competências, habilidades e conhecimentos, mediado por um preceptor. O preceptor, então, é o profissional da saúde que acompanha diretamente os residentes nos cenários e articula a prática ao conhecimento científico, sendo considerado um dos protagonistas do processo de ensino-aprendizagem das $\mathrm{RMS}^{18}$.

A presente pesquisa visa refletir sobre a percepção de residentes e preceptores quanto ao trabalho multiprofissional e interprofissional, a partir de uma experiência de Residência Multiprofissional em Saúde Hospitalar, em uma capital do Nordeste do Brasil. 


\section{Metodologia}

Trata-se de um estudo exploratório de natureza qualitativa ${ }^{19}$. A pesquisa foi desenvolvida em um hospital pertencente a uma Instituição de Ensino Superior que é referência no Estado, com residentes e preceptores (trabalhadores da saúde) das três ênfases que compõem a RIMUSH, distribuídas sob a forma de linhas de cuidado: Atenção à Saúde da Criança e do Adolescente; Atenção à Saúde do Idoso; e Atenção ao Paciente Crítico.

O desenvolvimento do currículo na RIMUSH engloba apresentação mensal de seminário integrador, abrangendo as três ênfases mencionadas. Tal atividade é pautada na vivência dos residentes; nos respectivos cenários de prática, incluindo o compartilhamento de Projetos Terapêuticos Singulares (PTS); e no conhecimento acerca da rotina do serviço ou outros projetos que tenham sido desenvolvidos. Esta ferramenta educacional visa promover uma maior integração entre os residentes, divulgar as ações desenvolvidas e ampliar o debate orientado pela práxis.

Além disso, no cronograma de atividades da residência, há programação para o desenvolvimento de tutorias, tanto por ênfase quanto por núcleo profissional, vislumbrando discussões e aprofundamento sobre temas vinculados ao que acontece na realidade vivenciada.

Associados ao componente teórico da carga horária da residência, existem, ainda, os módulos transversais, cujas abrangências perpassam as três ênfases. Vale mencionar que, em todas as estratégias pedagógicas adotadas na RIMUSH, há preconização da utilização das metodologias ativas de ensino-aprendizagem.

Os sujeitos voluntariados a participar do estudo foram os residentes da RIMUSH matriculados em seu segundo ano e os trabalhadores do hospital com experiência mínima de um ano como preceptores.

Nesse sentido, foi utilizada a técnica de Grupo Focal (GF) como estratégia de produção de dados qualitativos, cujo desenvolvimento de entrevistas grupais mediadas por um facilitador está adequado aos estudos, visando entender: atitudes, preferências, necessidades e sentimentos, e aprofundando a compreensão sobre o tema em análise ${ }^{20}$.

Foram realizados dois GF. Do primeiro - com duração aproximada de 55 minutos - participaram nove preceptores, pertencentes às três seguintes categorias profissionais: Enfermagem, Nutrição e Serviço Social. Já o segundo, incluiu 11 residentes, os quais dialogaram por 75 minutos. Nesse caso, foram cinco as categorias profissionais: Enfermagem, Farmácia, Fisioterapia, Fonoaudiologia e Serviço Social. A condução do GF foi baseada no referencial de Stalmeijer et al. ${ }^{20}$.

O roteiro dos GF pautou-se: na multiprofissionalidade, na interprofissionalidade, nos espaços da residência onde esses conceitos foram colocados em prática, e nas possíveis implicações do trabalho multiprofissional e interprofissional no cotidiano dos serviços e para a formação.

Os GF foram gravados e, posteriormente, transcritos, na íntegra. Visando manter a privacidade e o sigilo da identidade dos atores envolvidos na pesquisa, adotou-se a nomeação 'Grupo Focal P' para preceptores, e 'Grupo Focal R', para residentes.

A análise de conteúdo foi realizada seguindo o que preconiza Bardin ${ }^{21}$ : a pré-análise, a exploração do material e o tratamento dos resultados. Realizaram-se a pré-análise do material coletado e a leitura flutuante das transcrições. Em seguida, procedeu-se à exploração do material. A terceira e última fase foi a do tratamento dos resultados obtidos e interpretados.

Foi observada a Resolução 466/12, do Conselho Nacional de Saúde ${ }^{22}$, e a pesquisa foi aprovada no Comitê de Ética e Pesquisa, obtendo parecer favorável (Certificado de Apresentação para Apreciação Ética). Os sujeitos voluntários participaram do estudo após a assinatura do Termo de Consentimento Livre Esclarecido.

\section{Resultados e discussões}

Esta seção será apresentada com base em cinco categorias predefinidas e identificadas no decorrer do processo de análise: As dimensões da multiprofissionalidade e da interprofissionalidade; (Re) 
conhecendo o papel dos residentes multiprofissionais nos cenários de prática; A preceptoria no âmbito da RMS; Processo avaliativo na residência: desafios e conquistas; e As potencialidades da RMS no contexto do ensino-serviço.

\section{As dimensões da multiprofissionalidade e da interprofissionalidade}

Extrapolar a lógica do trabalho uniprofissional, no Brasil, ainda é um desafio. Neste contexto, a EIP tem um significado singular ${ }^{8}$, que reforça os ideários do SUS e aponta caminhos a serem trilhados por ela na formação em serviço, como é o caso das RMS.

Trabalhar no mesmo ambiente e estar junto em uma atividade ou ação não significa efetivar a EIP. Assim, é muito importante adotar a interprofissionalidade como estratégia de trabalho e de formação, vislumbrando aonde se quer chegar e propondo passos a serem dados. O desafio é ainda maior ao se pensar em residência multiprofissional em ambiente hospitalar, onde a EIP vislumbra otimizar a assistência integral prestada ao usuário, por meio da promoção de processos de formação pautados na prática colaborativa ${ }^{8}$.

"[...] quando a gente pode contar com uma equipe que tem vários núcleos profissionais, por si só, eu acho que isso é uma multiprofissionalidade [...]. Quando a gente consegue sentar essa equipe, de vários núcleos, para atender de forma sistemática, qualitativa, um usuário, e cada um vai contribuir [...] a gente atinge a interprofissionalidade". (Grupo Focal P)

“[...] multiprofissionalidade, o que se sobressai é aquela ideia de que 'tão juntos, mas não constroem uma coisa juntos, de uma forma, é... horizontal [...]. Enquanto que o prefixo 'inter', ele é muito mais amplo, né?! [...] ele prescinde da participação de todos, [...] respeitando mesmo cada um". (Grupo Focal R)

Os depoimentos corroboram a definição da interprofissionalidade, atuação preconizada pela RMS, que resulta na otimização do cuidado em saúde com vistas à saúde integral do usuário, por meio do trabalho interacional da equipe, todavia, considerando as especificidades dos núcleos profissionais-9,23-25.

A inserção dos residentes em um processo de trabalho já estabelecido, marcado pela acentuada multiprofissionalidade, torna-se muito mais desafiadora. Os preceptores se deparam com novas formas de aprender e ensinar, como, também, de trabalhar em saúde, e os residentes sentem dificuldade para o exercício do trabalho interprofissional.

“[...] nós, residentes multiprofissionais, temos que levar a multiprofissionalidade pra o serviço, o que, na minha visão, deveria ser o contrário [...]". (Grupo Focal R)

Embora discussões acerca da multiprofissionalidade e da interprofissionalidade venham se acentuando nos últimos anos, este movimento ainda se mostra gradual quando o panorama analisado passa a ser o componente prático. Em consonância com o explanado, as RMS emergiram como alternativas para favorecer o desenvolvimento de profissionais com habilidades para o trabalho em equipe ${ }^{13,25}$, pretendendo fomentar uma formação libertadora, pautada no trabalho vivo, vinculado às tecnologias leves que envolvem a saúde ${ }^{26}$.

Os relatos dos residentes e preceptores mostram que, embora compreendam o conceito, a prática ainda é um desafio a ser perseguido. Reafirmam a lacuna entre o trabalho desenvolvido por equipes e o mero aglutinamento de profissionais, sendo imprescindível articular ações entre os núcleos para a efetivação da interprofissionalidade ${ }^{27}$. Às vezes, as equipes não atuam interprofissionalmente e ainda questionam a tentativa desse novo fazer. 
"[...] só que essa equipe multi, trabalhando, é cada um fazendo o seu, na sua caixinha, em todo momento". (Grupo Focal R)

"[...] mas os profissionais de todo lugar que a gente vai, [...] eles acham, às vezes, que a gente 'tá querendo fugir da assistência, porque a gente 'tá fazendo uma atividade [...] como é a nossa visita". (Grupo Focal R)

Assim, a residência tem proporcionado não só a formação em serviço para os residentes, como, também, a reflexão sobre o processo de trabalho, da parte dos preceptores. Logo, visar à promoção da efetivação da EIP é favorecer um espaço de aprendizado coletivo para todos os envolvidos, incentivando a interação entre as disciplinas, mediadas pelo diálogo e pela cooperação entre os profissionais da saúde.

A implementação da RMS tende a favorecer a reflexão sobre a reorganização do trabalho, potencializando as práticas colaborativas e suas implicações na atenção à saúde ${ }^{28}$.

Por meio das metodologias ativas, os processos pedagógicos relacionam-se com a resolução de problemas de forma crítica e reflexiva ${ }^{29,30}$, no intuito de promover a interação entre os atores, com foco não só no aspecto cognitivo do conhecimento, mas, também, assumindo a necessidade do desenvolvimento de outras habilidades interpessoais e atitudes para o trabalho em equipe, compreendendo o processo de trabalho em saúde em grupo e a interprofissionalidade ${ }^{13,31}$. Assim, os sujeitos problematizam sua práxis, tornando-se capazes de transformá-la, e, ao mesmo tempo, transformarem a si mesmos ${ }^{30}$.

Conforme relato dos grupos focais, as ferramentas que poderiam auxiliar na efetivação da multiprofissionalidade e da interprofissionalidade permeiam as metodologias interacionistas que fomentam a EIP, fazendo do processo ensino-aprendizagem algo prazeroso, estimulante e potencializador da prática crítico-reflexiva.

Nessa esfera, o PTS é uma ferramenta de organização da gestão do cuidado em saúde, instituída entre as equipes que efetivam este cuidado. A partir do diálogo, os trabalhadores envolvidos compartilham saberes e práticas, e acompanham, de forma longitudinal, os $\operatorname{casos}^{32,33}$. Como o próprio nome ressalta, trata-se de uma discussão prospectiva sobre o caso, de forma não fragmentada e isolada, por núcleos profissionais, procurando responder às demandas do usuário ${ }^{34}$.

“[...] que já entra outro conceito: de clínica ampliada, que é uma coisa que os residentes vêm trazendo pr'a gente [...]". (Grupo Focal P)

"[...] fizemos um PTS desse paciente e a gente botou a rede e o resultado, a equipe, sabe [...] realmente a gente trabalhou de forma multi e interprofissional". (Grupo Focal R)

Tais questões perpassam o enfatizado por Reeves ${ }^{7}$, ao elencar diversos métodos de aprendizado que podem ser utilizados para o alcance da EIP: aprendizagem baseada em seminário; aprendizagem baseada em observação (shadowing); aprendizagem baseada em problemas; aprendizagem baseada em simulação; e aprendizagem baseada na prática clínica.

Nesse âmbito, a discussão em pequenos grupos sobre o vivenciado, seja em espaços de tutoria ou na própria preceptoria de ênfase ou núcleo profissional, sobressai-se como estratégia educacional potente ${ }^{35}$, bem como o planejamento do conjunto de ações ${ }^{36}$. Isto implica a importância de se utilizarem vários dos métodos explicitados, pautando-os na complementaridade das especificidades profissionais e, assim, na qualificação e na integralidade à assistência prestada ${ }^{8}$.

Entretanto, a utilização do PTS, por vezes, não foi acolhida pelos trabalhadores dos cenários de prática, sendo necessária, portanto, a Educação Permanente (EP) dos preceptores, no que diz respeito ao seu desenvolvimento docente, como, também, a discussão sobre a organização do processo de trabalho em saúde e as tecnologias que favoreçam o trabalho colaborativo e a EIP. Pesquisa realizada por Fernandes et al. ${ }^{37}$ também observou dificuldade no processo de trabalho com base na reprodução de práticas dos núcleos profissionais, isoladamente, distanciando-se dos preceitos da RMS. 


\section{(Re)conhecendo o papel dos residentes multiprofissionais nos cenários de prática}

A elaboração dos programas de residência, geralmente, ocorre em meio a articulações com diversos atores, como gestores e trabalhadores da Rede de Atenção à Saúde (RAS), gestores acadêmicos e docentes ${ }^{38}$. No entanto, apesar desta configuração, o cuidado com a socialização das informações sobre as atividades da residência multiprofissional deve ser constante, no sentido de evitar fragilidades na inserção e no vínculo inicial dos residentes com os serviços, além de uma visão equivocada a respeito da RMS.

Feuerwerker ${ }^{26}$ esclarece que, de fato, a residência pode ter enfoque meramente assistencial. Todavia, o intuito é que ela seja inventiva na esfera do desenvolvimento das tecnologias do cuidado e dos aspectos que a circundam.

O entendimento de que o residente atuaria, simplesmente, compondo a equipe do cenário de prática, inclusive, contribuindo para preencher lacunas ligadas ao dimensionamento de pessoal, reflete as fragilidades que envolvem a gestão e a tímida apropriação da função dos residentes. Esta compreensão pode fomentar a uniprofissionalidade e o pouco entendimento quanto à inserção e ao papel dos residentes no contexto dos serviços de saúde.

“[...] sim, mas vocês vão fazer o que, aqui? É... vocês vão conseguir vaga no HU pra, pros nossos pacientes? [...] o que esse povo vai querer fazer aqui? Num é estagiário, num quer assumir o serviço e ainda vem dando ideia. Que é isso?". (Grupo Focal R)

Pesquisa realizada com enfermeiros e técnicos de enfermagem que acompanhavam o trabalho de residentes de enfermagem evidenciou, também, a dualidade ou confusão de entendimento sobre o residente: seria ele estudante ou profissional ${ }^{39}$ ? De fato, é preciso definir os papéis de cada ator na residência, inclusive, determinando suas atribuições e competências.

Ante o exposto, faz-se premente a existência de discussões cotidianas sobre o arcabouço legal da RMS, vislumbrando-se, inclusive, a agregação de atores que possam ser multiplicadores de sua proposta e fomentadores de estratégias que intentem sua efetivação nos serviços da Rede de Atenção à Saúde (RAS).

Dessa forma, são necessários processos de pactuações com os trabalhadores do SUS envolvidos na residência e com gestores de serviços de saúde e de instâncias acadêmicas, para a elaboração da proposta da própria residência, bem como do desenvolvimento de EP para os preceptores ${ }^{37,39}$. A EIP insere-se como questão central nestes processos, que devem, inclusive, reiterar o papel das residências como transformadoras das práticas dos serviços. E, tendo em vista que os programas geralmente perpassam diversos cenários, esse movimento provocaria uma qualificação dos profissionais da RAS.

Além disso, construir processos formativos que incluam os preceptores, possivelmente, refletirá na qualificação das discussões com os residentes e na melhoria de ambos nos cenários em que estiverem inseridos. Estes processos devem ser orientados pelo desenvolvimento de domínios por competência, com foco na EIP, no sentido de discutir habilidades, atitudes, valores, decisões, que estimulam a prática colaborativa do cuidado em saúde ${ }^{11,16}$.

Contudo, avanços já foram conquistados e demonstram a possibilidade de mudanças expressivas nesse contexto, como a oferta do curso de preceptoria.

\section{A preceptoria no âmbito da RMS}

O protagonismo do preceptor é de fundamental importância na RMS, uma vez que realiza a interlocução residente-serviço e potencializa as discussões e reflexões acerca das vivências, facilitando o processo de ensino-aprendizagem. Contudo, a integração ativa dos profissionais dos serviços, nesta perspectiva, ainda é um desafio, visto - entre outros aspectos - o frágil incentivo institucional, a extenuante jornada de trabalho e a oferta diminuta de desenvolvimento docente e formação de preceptoria $^{38}$. 
Além disso, a atuação do preceptor pode assumir diversas configurações, causando dúvida, estranhamento e insegurança sobre qual seria o seu papel frente à RMS. Do ponto de vista do próprio preceptor, e também dos residentes, esta reflexão é feita e pode ser discutida, a partir de espaços de diálogo que favoreçam a construção conjunta.

“[...] a gente tem uma dúvida assim: O que é ser preceptor? Preceptor é aquele que acompanha diretamente? Aquele que está longe? [...] nós estamos aprendendo a ser preceptor, né?! A gente "tá construindo isso". (Grupo Focal P)

"É aí onde vem aquela questão: preceptor de campo é aquele para a qual ele foi nomeado? Ou é aquele que, independente do seu núcleo específico, ele lhe dá um suporte?". (Grupo Focal R)

Ressalta-se que, apesar da variedade de definições conferidas ao preceptor, o que não se pode perder de vista é o seu componente pedagógico dentro do processo educativo, seja enquanto fomentador da clínica ou facilitador de outros aspectos ${ }^{40}$. Também emerge das falas, em especial do último trecho exposto, uma reflexão conceitual quanto ao núcleo ou campo de atuação do preceptor, devendo-se esclarecer que o núcleo é a especificidade de determinada área do conhecimento, enquanto campo seria onde os profissionais desses núcleos atuam, apoiando-se para a resolutividade teórico-prática de suas demandas ${ }^{41}$.

$\mathrm{Na}$ esfera das dificuldades para uma atuação eficaz desse ator, cabe ressaltar a questão do acúmulo de funções.

"[...] eu acumulo diversas funções e que eu, muitas vezes, preciso está do lado do residente e eu não estou". (Grupo Focal P)

Pesquisa realizada com preceptores apontou para o fato de a escassez de tempo representar uma expressiva fragilidade para o desempenho da preceptoria ${ }^{42}$. Diante das falas, infere-se o possível prejuízo que a sobrecarga de trabalho dos preceptores promove ao processo de formação dos profissionais envolvidos na residência ${ }^{28}$.

Estudo sobre a interpreceptoria na Estratégia Saúde da Família, com profissionais de nível Superior ${ }^{28}$, constatou que os preceptores reconheceram as fragilidades de sua formação acadêmica, no tocante à interprofissionalidade ${ }^{28}$. Diante dessa demanda, houve a necessidade de alinhamento teórico na capacitação profissional, mesma característica exposta em pesquisa realizada por Barreto e Marco ${ }^{43}$, cujos preceptores indicaram a sua inserção em um movimento de EP com foco na educação na saúde.

“[...] esses residentes vêm com ferramentas novas pra os preceptores, que até hoje nós ainda não temos o domínio. [...] por conta de oportunidade de um curso de preceptoria que foi ofertado, e que não abrangeu todos os preceptores". (Grupo Focal P)

Fomentar a existência de EIP nas áreas social e da saúde faz-se primordial, uma vez que a aproximação dos profissionais com o ensino de cunho libertador ainda se encontra incipiente, e que esses profissionais necessitam conquistar domínios e habilidades que orientem o trabalho colaborativo, vislumbrando o cuidado integral 744,45 .

Deve-se reconhecer que algumas ações nesse sentido vêm sendo desenvolvidas, entretanto, em número insuficiente e com poucos profissionais. Tal limitação pode relacionar-se à promoção da saída da zona de conforto no processo de trabalho implicada nesses espaços formativos e ao acúmulo de funções no ambiente de trabalho.

"Quem é envolvido com a residência, que 'tá procurando se capacitar, que 'tá nos momentos de formação, às vezes, você não é bem visto pelo resto da equipe porque você vem provocar uma mudança de rotina". (Grupo Focal P) 
Em pesquisa realizada por Jesus e Ribeiro ${ }^{46}$, os profissionais, após o processo de formação, consideraram-se instrumentalizados para uma atuação problematizadora no processo de trabalho. O mesmo ocorreu nos achados de Tracey e McGowan ${ }^{47}$, nos quais os preceptores sinalizaram a importância dos processos de atualização para a preceptoria.

Reforça-se o protagonismo que o preceptor possui na RMS, já que é um dos ativadores da constante construção do conhecimento, mediando-o por meio de uma relação dialógica com o residente e requerendo, para tanto, aporte teórico-metodológico adequado ${ }^{18}$.

\section{Processo avaliativo na residência: desafios e conquistas}

A RMS orienta suas avaliações nos preceitos das metodologias ativas de ensino-aprendizagem. Deve-se, pois, considerar a avaliação como um movimento complexo, que valoriza não somente os conhecimentos cognitivos, mas, também, os afetivos e os psicomotores inerentes a este tipo de método, bem como a relação com a capacidade de fazer e receber feedbacks $s^{48,49}$.

Entretanto, o modelo tradicional de ensino ainda permeia os espaços de formação. Apesar do que se preconiza na residência, o processo avaliativo ainda constitui uma ação verticalizada, desempenhada com incipiente diálogo entre residentes e preceptores, bem como fragilizada no tocante à provocação de análise crítica e reflexiva sobre o processo vivenciado, ao deslocamento obtido e aos domínios e competências que precisam ser mais bem desenvolvidos pelo residente.

\footnotetext{
"Seria melhor que fosse de mês em mês. Depende do tempo que ele passar... Uma vez ao mês, e assim você pode dizer o que pode melhorar e, no mês seguinte, poderia estar diferente... Só avaliação no final, pois eu tive que avaliar alguém que já tinha saído do cenário de prática... Avaliação deve ser construtiva, deve ser contínua". (Grupo Focal P)
}

Nesse contexto, ampliar o diálogo na perspectiva da avaliação faz-se necessário, com vistas a provocar uma transformação na prática. Deste modo, o processo de trabalho na RMS passa a ser refletido, e o conhecimento construído significativamente, já que a transmissão deste não mais se constitui em modelo educacional recomendado ${ }^{50}$.

Durante o GF, houve questionamento sobre os processos avaliativos, no escopo de como e quando estavam ocorrendo. Isto posto, foi possível verificar conquistas, além de reconhecer a necessidade de tais processos serem contínuos e construtivos. Ressalta-se a disponibilidade de diversas abordagens avaliativas, que possibilitam a construção de metas de aprendizagem e verificação do cumprimento dos objetivos de aprendizagem, antes, durante e depois do processo de vivência ${ }^{11}$.

Assim sendo, aspectos quantitativos, quando extrapolados e com ênfase nas abordagens horizontais e participativas, contemplando as fragilidades e potencialidades percebidas nas experiências vivenciadas e no sentido de estimular a aprendizagem dos atores envolvidos, são elementos que podem ser angariados em processo avaliativo inovador, adequado aos preceitos da $\mathrm{RMS}^{51}$.

Ainda nessas circunstâncias, a EIP pode exercer papel relevante na implementação de processos avaliativos, ao considerar elementos como o incentivo à transformação da cultura e procedimentos desempenhados pelos profissionais de saúde, que minimizem os entraves para o trabalho colaborativo e a aspiração pelo aperfeiçoamento da estrutura pedagógica, aspectos que implicam o deslocamento com vistas à qualificação dos preceptores e residentes ${ }^{10}$.

\section{As potencialidades da RMS no contexto do ensino-serviço}

As questões apreendidas convergiram para a compreensão de que, isoladamente, os profissionais não conseguem prestar um cuidado qualificado, uma vez que os usuários e suas necessidades de saúde são dotados de complexidade, e, apenas a partir do diálogo entre os atores é que intervenções efetivas poderão se concretizar ${ }^{52}$.

Nesse intuito, preceptores reconhecem, apesar dos desafios existentes, que a RMS incentiva a reorientação de práticas, com vistas à consecução dos princípios e diretrizes preconizados pelo SUS. 
“[...] a residência, [...] veio pra ajudar nesse ponto, em alguns momentos, trabalha com inter... quando a residência 'tá lá sofrendo a influência dentro dos profissionais. Quando a residência se ausenta, a gente continua sendo multi". (Grupo Focal P)

Nesse escopo, a inquietação se comporta como um elemento marcante, mediante as ações propositivas dos residentes, que suscitam uma onda de anseio por EP nos serviços, considerando-se, inclusive, que a tomada de decisão perpassa os núcleos, e, diante de seus limites, extrapola para a interprofissionalidade ${ }^{36,50}$.

“Então, são projetos que é... incentiva até a gente que 'tá na prática. Diz assim: 'É possível fazer, né?!' E eles [residentes] vêm auxiliando a mudança de paradigmas dentro de mim, entendeu?". (Grupo Focal P)

$\mathrm{Na}$ perspectiva dos residentes, emergiram reflexões críticas quanto à potencialidade da residência como movimento de ensino-aprendizagem para si mesmos e, também, no cerne dos cenários de prática, embora a sua viabilização ainda exija mais envolvimento de seus atores.

“E aí, com o feedback que a gente deu, né?! Porque isso também é muito bom, você parar depois que você faz e sentar com o profissional: 'Olha, a gente fez e propôs isso assim, por causa disso, disso e disso'. E aí, elas puderam parar pra pensar: 'É, realmente, a gente não tem esse momento de parar pra pensar na nossa prática e outras soluções para além daquilo que a gente já 'tá acostumado'". (Grupo Focal R)

Portanto, reafirma-se que a RMS constitui um espaço de (re)construção de conhecimento e de transformação de práticas, concebida de forma articulada às demandas do SUS, visto ser fundamental dispor de profissionais que atendam aos problemas de saúde dos usuários, a partir de abordagens mais abrangentes, para além das dimensões biológicas. No contexto hospitalar, esta questão fica ainda mais evidente, considerando o predomínio do modelo médico-centrado e da assistência pautada em procedimentos. Cabe aos profissionais envolvidos pela RMS refletirem, permanentemente, sobre as seguintes declarações e indagações:

“Então, eu acho que envolver não só os residentes, os profissionais, mas os usuários desse processo, né?!, de entender o que... o que a residência é pro SUS? O que a residência pode fomentar? Em que sentido a integralidade pode ser vislumbrada, a partir dessa formação desses profissionais". (Grupo Focal R)

Os resultados da presente pesquisa foram apresentados à coordenação da RIMUSH, no sentido de balizar processos de desenvolvimento docente para os preceptores, contemplando metodologias ativas, incluindo a avaliação formativa e a gestão do processo de trabalho em hospital. Ressalta-se que participaram dos GF residentes da turma do segundo ano e, na ocasião, o curso de formação de preceptores estava iniciando suas atividades. Outros estudos podem ser realizados, no que diz respeito à avaliação da residência, buscando identificar os desdobramentos e as repercussões gerados pela RIMUSH no hospital, além do impacto da capacitação de preceptores no processo ensinoaprendizagem na residência.

\section{Considerações finais}

Entre os preceitos da RMS, está o fomento do trabalho multiprofissional e interprofissional, sendo necessária a apropriação teórica e prática dessas dimensões, por todos os atores envolvidos neste processo, vislumbrando, inclusive, a concretização de princípios e diretrizes do SUS. Percebe-se que o trabalho em saúde, na RAS, necessita de profissionais que compreendam a importância das práticas colaborativas na produção do cuidado em saúde. 
A percepção do preceptor sobre residência contemplou reflexões sobre o processo de trabalho estabelecido. A residência foi capaz de trazer ferramentas que potencializam o trabalho interprofissional e a integralidade do cuidado em saúde, em se tratando de atenção terciária, em um hospital-escola. Se, por um lado, trata-se de um grupo de residentes capacitados por meio de sua formação em serviço, por outro lado, há o trabalhador/preceptor também modificado, pela mobilização, para a práxis.

Nessa perspectiva, compreender a percepção de preceptores e residentes constatou-se estratégico, uma vez que viabilizou a identificação de fragilidades e fortalezas, propulsores de movimentos de planejamento e reestruturação do(s) programa(s) de residência. Neste cenário, a EP emerge como uma dimensão fundamental, podendo ampliar o leque de desdobramentos favoráveis advindos da RMS. Os resultados deste estudo indicaram avanços e desafios relativos à multiprofissionalidade e à interprofissionalidade no âmbito de uma residência em saúde hospitalar.

\section{Colaboradores}

Thaise Anataly Maria de Araújo participou da concepção e desenho do estudo, coleta e análise e interpretação dos dados, e participou ativamente da escrita e da revisão e aprovação final do trabalho. Ana Claudia Cavalcanti Peixoto de Vasconcelos, Talitha Rodrigues Ribeiro Fernandes Pessoa participaram da discussão dos resultados com os demais, escrita e revisão e aprovação final do trabalho. Franklin Delano Soares Forte participou da concepção e desenho do estudo, coleta, análise e interpretação dos dados, e participou ativamente da escrita e da revisão e aprovação final do trabalho.

\section{Referências}

1. Interprofessional Education Collaborative Expert Panel. Core competencies for interprofessional collaborative practice: Report of an expert panel. Washington, D.C.: Interprofessional Education Collaborative; 2011.

2. Frenk J, Chen L, Bhutta ZA, Cohen J, Crisp N, Evans T, et al. Health professionals for a new century: transforming education to strengthen health systems in an interdependent world. Lancet. 2010; 376(9756):1923-58.

3. Bezerra TCA. Programa de residência multiprofissional em saúde: construção de um instrumento avaliativo [dissertação]. Recife: Instituto de Medicina Integral Prof. Fernando Figueira; 2011.

4. Peduzzi M, Norman IJ, Germani ACCG, Silva JAM, Souza GC. Educação interprofissional: formação de profissionais de saúde para o trabalho em equipe com foco nos usuários. Rev Esc Enferm USP. 2013; 47(4):977-83.

5. Alvarenga JPO, Meira AB, Fontes WD, Xavier MMFB, Trajano FMP, Neto GC, et al. Multiprofissionalidade e interdisciplinaridade na formação em saúde: vivências de graduandos no estágio regional interprofissional. Rev Enferm UFPE. 2013; 7(10):5944-51.

6. Batista NA. Educação interprofissional em saúde: concepções e práticas. Cad FNEPAS. 2012; 2:25-8. 
7. Reeves $S$. Why we need interprofessional education to improve the delivery of safe and effective care. Interface (Botucatu). 2016; 20(56):185-96.

8. Costa MV. A educação interprofissional no contexto brasileiro: algumas reflexões. Interface (Botucatu). 2016; 20(56):197-8.

9. Câmara AMCS, Cyrino AP, Cyrino EG, Azevedo GD, Costa MV, Bellini MIB, et al. Educação interprofissional no Brasil: construindo redes formativas de educação e trabalho em saúde. Interface (Botucatu). 2016; 20(56):5-8.

10. Organização Mundial da Saúde. Redes de profissões de saúde. Enfermagem e obstetrícia. Recursos humanos para a saúde. Marco para ação em educação interprofissional e prática colaborativa. Genebra, CH: RPSEORHS; 2010.

11. Jecker J, Adams-Carpino G, Berry S, Brigss M, Chisholm B, Clack J, et al. Interprofessional learning guide. Ontário: Northern Ontario School of Medicine; 2015.

12. Gilbert JH. Interprofessional learning and higher education structural barriers. J Interprof Care. 2005; 19(s1):87-106.

13. Motta LB, Pacheco LC. Integrating medical and health multiprofessional residency programs: the experience in building an interprofessional curriculum for health professionals in Brazil. Educ Health. 2014; 27(1):83-8.

14. Van Schaik S, Plant J, O'Brien B. Challenges of interprofessional team training: a qualitative analysis of residents' perceptions. Educ Health. 2015; 28(1):52-7.

15. Reeves S, Fletcher S, Barr H, Birch I, Boet S, Davies N, et al. A BEME systematic review of the effects of interprofessional education: BEME Guide No. 39. Med Teach. 2016; 38(7):656-68.

16. Ministério da Saúde (BR). Lei no 11.129, de 30 de junho de 2005. Institui a Comissão Nacional de Residência Multiprofissional em Saúde no âmbito do Ministério da Educação. Diário Oficial da União, 30 Jun 2005.

17. Ministério da Saúde (BR). Portaria Interministerial $n^{\circ} 1077$, de 12 de novembro de 2009. Dispõe sobre a residência multiprofissional em saúde e a comissão nacional de residência multiprofissional em saúde. Diário Oficial da União, 12 Nov 2009.

18. Ribeiro KRB, Prado ML. A prática educativa dos preceptores nas residências em saúde: um estudo de reflexão. Rev Gaucha Enferm. 2013; 34(4):161-5.

19. Gil AC. Métodos e técnicas de pesquisa social. São Paulo: Atlas; 2001.

20. Stalmeijer RE, Mcnaughton N, Van Mook WN. Using focus groups in medical education research: AMEE Guide n 91. Med Teach. 2014; 36(11):923-39.

21. Bardin L. Análise de conteúdo. Lisboa: Edições 70; 2009.

22. Ministério da Saúde (BR). Resolução no 466 do Conselho Nacional de Saúde, de 12 de dezembro de 2012. Diretrizes e normas regulamentadoras de pesquisa envolvendo seres humanos. Diário Oficial da União. 12 Dez 2012.

23. Amatuzzi MLL, Barreto MCC, Litvoc J, Leme LEG. Linguagem metodológica: parte 2. Acta Ortop Bras. 2006; 14(2):108-12.

24. Batista NA, Batista SHSS. Educação interprofissional na formação em saúde: tecendo redes de práticas e saberes. Interface (Botucatu). 2016; 20(56):202-4.

25. Casanova IA, Batista NA, Ruiz-Moreno L. Formação para o trabalho em equipe na residência multiprofissional em saúde. ABCS Health Sci. 2015; 40(3):229-33.

26. Feuerwerker L. No olho do furacão: contribuição ao debate sobre a residência multiprofissional em saúde. Interface (Botucatu). 2009; 13(28):229-30. 
27. Peduzzi M. Trabalho em equipe de saúde no horizonte normativo da integralidade, do cuidado e da democratização das relações de trabalho. 161-77. In: Pinheiro R, Barros MEB, Mattos RA. Trabalho em equipe sob o eixo da integralidade: valores, saberes e práticas. Rio de Janeiro: CEPESC; 2007.

28. Bispo EPF, Tavares CHF, Tomaz JMT. Interdisciplinaridade no ensino em saúde: o olhar do preceptor na Saúde da Família. Interface (Botucatu). 2014; 18(49):337-50.

29. Masetto MT. Competência pedagógica do professor universitário. São Paulo: Summus; 2003.

30. Mitre SM, Siqueira-Batista R, Girardi-de-Mendonça JM, Morais-Pinto NM, Meirelles $C A B$, Pinto-Porto $C$, et al. Metodologias ativas de ensino-aprendizagem na formação profissional em saúde: debates atuais. Cienc Saude Colet. 2008; 13(s2):2133-44.

31. Reeves S. Ideas for the development of the interprofessional field. J Interprof Care. 2010; 24(3):217-19.

32. Ministério da Saúde (BR). Secretaria de Atenção à Saúde. Núcleo Técnico da Política Nacional de Humanização. Clínica ampliada, equipe de referência e projeto terapêutico singular. Brasília: Ministério da Saúde; 2007.

33. Campos GWS, Amaral MA. A clínica ampliada e compartilhada, a gestão democrática e redes de atenção como referenciais teórico-operacionais para a reforma do hospital. Cienc. Saude Colet. 2007; 12(4):849-59.

34. Pinto DM, Jorge MSB, Pinto AGA, Vasconcelos MGF, Cavalcante CM, Flores AZT et al. Projeto terapêutico singular na produção do cuidado integral: uma construção coletiva. Texto Contexto Enferm. 2011; 20(3):493-502.

35. Lobato CP, Melchior R, Baduy RS. A dimensão política na formação dos profissionais de saúde. Physis. 2012; 22(4):1273-91.

36. Silva CT, Terra MG, Camponogara S, Kruse MHL, Roso CC, Xavier MS. Educação permanente em saúde a partir de profissionais de uma residência multidisciplinar: estudo de caso. Rev Gaucha Enferm. 2014; 35(3):49-54.

37. Fernandes MNS, Beck CLC, Weiller TH, Viero V, Freitas PH, Prestes FC. Sofrimento e prazer no processo de formação de residentes multiprofissionais em saúde. Rev Gaucha Enferm. 2015; 36(4):90-7.

38. Cheade MFM, Frota OP, Loureiro MDR, Quintanilha ACF. Residência multiprofissional em saúde: a busca pela integralidade. Cogitare Enferm. 2013; 18(3):592-5.

39. Drago LC, Salum RL, Andrade SRA, Medeiros M, Marinho MM. A inserção do residente em enfermagem em uma unidade de internação cirúrgica: práticas e desafios. Cogitare Enferm. 2013; 18(1):95-101.

40. Autonomo FROM, Hortale VA, Santos GB, Botti SHO. A Preceptoria na formação médica e multiprofissional com ênfase na atenção primária - Análise das Publicações Brasileiras. Rev Bras Educ Med. 2015; 39(2):316-27.

41. Campos GWS. Saúde pública e saúde coletiva: campo e núcleo de saberes e práticas. Cienc Saude Coletiva. 2000; 5(2):219-30.

42. Hartzler ML, Ballentine JE, Kauflin MJ. Results of a survey to assess residency preceptor development methods and precepting challenges. Am J Health Syst Pharm. 2015; 72(15):1305-14.

43. Barreto VHL, Marco MA. Visão de preceptores sobre o processo de ensinoaprendizagem no internato. Rev Bras Educ Med. 2014; 38(1):94-102.

44. Pippitt K, Moloney-Johns A, Jalilibahabadi S, Gren LH. Collaboration versus competition: An interprofessional education experience. Fam Med. 2015; 47(4):298-301. 
45. Bengtsson M, Carlson E. Knowledge and skills needed to improve as preceptor: development of a continuous professional development course - a qualitative study part I. BMC Nurs. 2015; 14:51.

46. Jesus JCM, Ribeiro VMB. Uma avaliação do processo de formação pedagógica de preceptores do internato médico. Rev Bras Educ Med. 2012; 36(2):153-61.

47. Tracey JM, McGowan IW. Preceptors' views on their role in supporting newly qualified nurses. Br J Nurs. 2015; 24(20):998-1001.

48. Higa EFR, Hafner MLMB, Tonhom SFR, Taipeiro EF, Moreira HM, Guimarães APC, et al. Indicadores de avaliação em gestão e saúde coletiva na formação médica. Rev Bras Educ Med. 2013; 37(1):52-9.

49. Silva RHA, Scapin LT. Utilização da avaliação formativa para a implementação da problematização como método ativo de ensino-aprendizagem. Estud Aval Educ. 2011; 22(50):537-52.

50. Forte FDS, Pessoa TRRF, Freitas CHSM, Pereira CAL, Carvalho Junior PM. Reorientação na formação de cirurgiões-dentistas: o olhar dos preceptores sobre estágios supervisionados no Sistema Único de Saúde (SUS). Interface (Botucatu). 2015; 19(s1):831-43.

51. Melo MC, Queluci GC, Gouvêa MV. Problematizing the multidisciplinary residency in oncology: a practical teaching protocol from the perspective of nurse residents. Rev Esc Enferm USP. 2014; 48(4):706-14.

52. Silva JC, Contim D, OhI RIB, Chavaglia SRR, Amaral EMS. Percepção dos residentes sobre sua atuação no programa de residência multiprofissional. Acta Paul Enferm. 2015; 28(2):132-8.

Araújo TAM, Vasconcelos ACCP, Pessoa TRRF, Forte FDS. Multi-profesionalidad e inter-profesionalidad en una residencia hospitalaria: la mirada de residentes y preceptores. Interface (Botucatu). 2017; 21(62):601-13.

Se buscó comprender la percepción de residentes y preceptores sobre la multiprofesionalidad y la inter-profesionalidad de una Residencia Integrada Multi-profesional en Salud Hospitalaria. Se realizó un estudio con abordaje cualitativo, envolviendo al grupo de opinión como estrategia de producción de datos, analizados por medio del análisis de contenido de Bardin. En la práctica, los conceptos sobre multi-profesionalidad e interprofesionalidad todavía están fragilizados. No obstante, se enumeraron herramientas que pueden auxiliar en esa efectivación, incluso con el objetivo del fomento del trabajo colaborativo. Hay confusión y dualidad en relación al (re)conocimiento del papel de los residentes en los escenarios de práctica. El preceptor es un importante actor en las Residencias Multi-profesionales en Salud. A pesar de los avances percibidos, la viabilidad de la inter-profesionalidad todavía se configura como un desafío del sector salud. En ese contexto, los procesos formativos continuos, con base en la educación inter-profesional, constituyen herramientas estratégicas.

Palabras clave: Trabajo en equipo. Preceptoría. Educación inter-profesional. Colaboración inter-profesional. Residencia multi-profesional en salud. 
